\title{
HOMENAJE A DONALD JACKSON
}

\section{Recuerdos de Donald Jackson}

\author{
Mauricio Massone $e^{1,2}$
}

La vida nos obsequió a Donald Jackson. Qué gran regalo para su familia, para Roxana Seguel, su compañera, para sus estudiantes, amigos y colegas, para la arqueología chilena. Un hombre que llegó a este mundo para vivir la arqueología con enorme pasión.

Con vocación profunda, con capacidad teórica, rigurosidad metodológica y perseverancia inagotable, fue construyendo el macizo edificio de la arqueología de Los Vilos y de toda la zona próxima. Tenía una gran capacidad para dimensionar en la medida precisa sus proyectos de investigación, para conseguir los objetivos que buscaba. En casi tres décadas nos dejó un modelo de cómo poder realizar un vasto programa de investigaciones arqueológicas y paleoambientales a escala regional, en el Norte Chico, con un conjunto de proyectos encadenados. Pero su manera de abordar la arqueología ha permitido, sin duda, que sus logros trasciendan el ámbito regional y nacional.

Organizó equipos multidisciplinarios, contando con el apoyo de Roxana Seguel, de César Méndez, de Antonio Maldonado y de tantos otros especialistas. Invitó a colegas externos para discutir distintos aspectos teóricos y metodológicos de sus proyectos. Formó a diferentes generaciones de jóvenes arqueólogos, sus alumnos del Departamento de Antropología de la Universidad de Chile; dirigió prácticas, tesis y a todos les brindó su dedicación y transmitió su pasión por la generación de nuevo conocimiento.

Su casa de Los Vilos era la base de operaciones para las campañas de terreno y la escuela de campo para tantos alumnos y para múltiples colegas invitados. Allí se organizaban las tareas diarias, se realizaban trabajos de conservación preventiva, análisis y documentación de materiales procedentes de terreno. En las noches la casa se transformaba en un centro de tertulias entre los participantes de

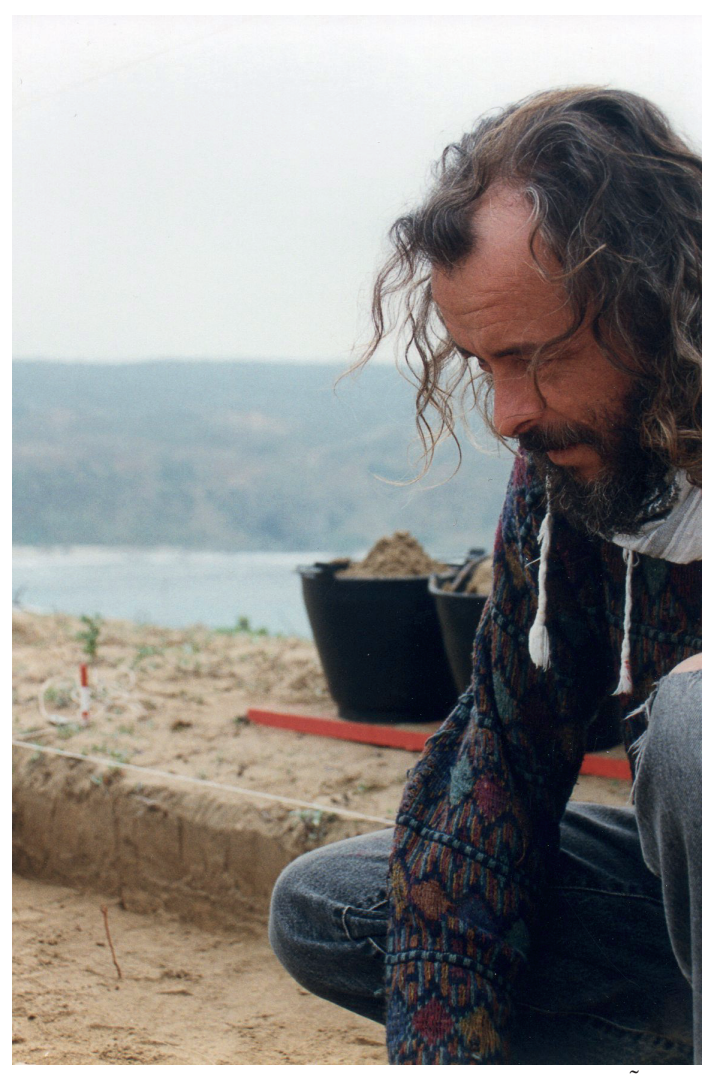

Donald reflexionando, durante la excavación en el sitio de Ñagué, Los Vilos (imagen de Mauricio Massone).

la campaña, donde se analizaban temas teóricos y metodológicos y donde había también espacio para conversar acerca de temas vivenciales. Era imprescindible además un buen asado con "quemas rituales", al final de cada período de terreno.

Los resultados de esas reflexiones nocturnas y la planificación diaria de las actividades científicas necesarias, eran las claves para los resultados que se obtenían año tras año. La búsqueda del sitio Santa

Museo de Historia Natural de Concepción, Dirección de Bibliotecas, Archivos y Museos, Concepción, Chile.

2 Centro de Estudios del Hombre Austral, Instituto de la Patagonia, Universidad de Magallanes, Magallanes, Chile.

mauricio.massone@gmail.com 


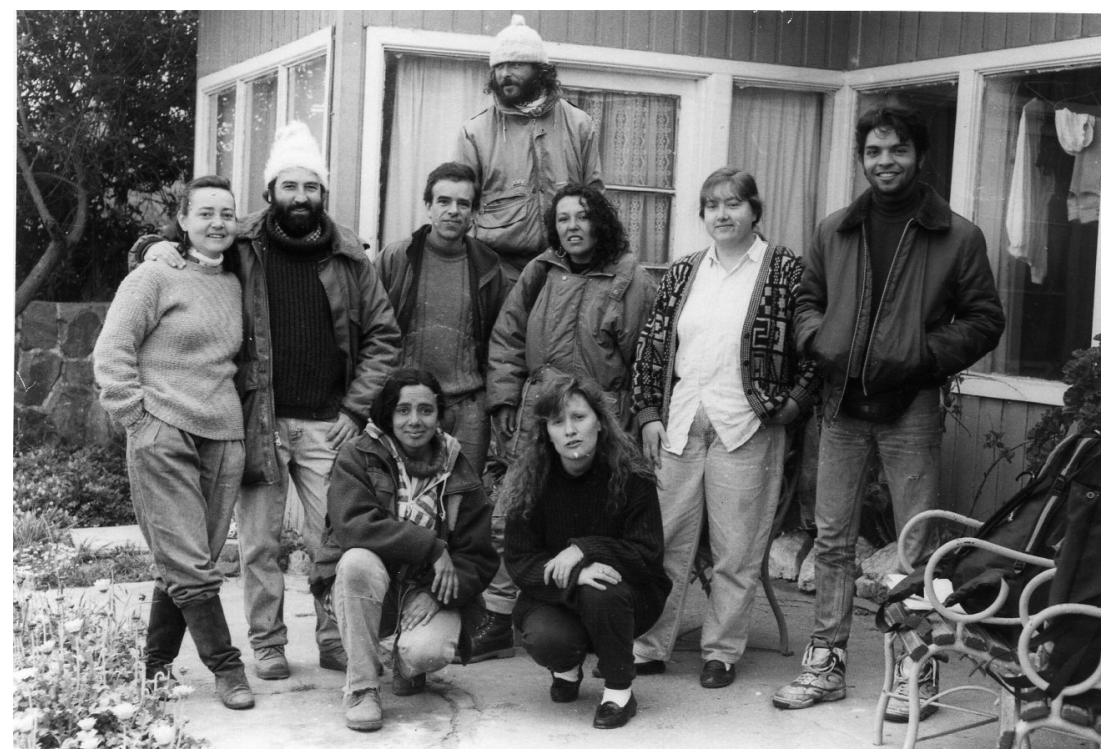

Donald en la casa de Los Vilos con Roxana Seguel y compañeros de estudio.

Julia en el marco de un proyecto sobre primeros poblamientos humanos y fauna extinta y la impecable excavación del sitio con los impresionantes registros de planta, constituyen un ejemplo puntual de su intuición arqueológica y luego de su esmero metodológico.

Pero Donald no era solo un arqueólogo destacado, era también un gran amigo de sus colegas. Se interesaba por lo que investigaban los demás, hacía preguntas sustantivas, opinaba, daba consejos, empujaba a sus pares a impulsar acciones de investigación y de publicación o difusión. Los que fuimos sus amigos percibimos siempre su entusiasmo, su estímulo y su afecto como persona muy cercana. Enfrentaba la vida con valentía y en algunos casos incluso en forma osada, superando muchas veces barreras difíciles. Si era necesario discutir o defender un punto de vista que consideraba importante podía mostrar toda su tenacidad.

En el plano personal, aún recuerdo que en el segundo semestre de 1987, me encontraba un día sentado en el laboratorio de la sección de Antropología en el Museo Nacional de Historia Natural, en Santiago, observando los materiales líticos del sitio Tres Arroyos de Tierra del Fuego, dispuestos sobre el mesón, para ser estudiados. Pensaba en la importancia de la información que encerraban dichos materiales para comprender algo más de los primeros grupos humanos que habían llegado al extremo sur del continente americano, ingresando a Tierra del Fuego cuando este territorio se encontraba conectado a Sur Patagonia, al final del Pleistoceno. Sabía que era imprescindible que ese estudio lo abordara un especialista en lítico.

Por una sincronía que parecía estar escrita en la imperceptible geometría del Universo, Donald Jackson apareció frente a la puerta de mi oficina procedente de Ecuador... allí comenzó nuestra larga amistad y los proyectos conjuntos. En ese momento recordé la gran impresión que me causó años antes un joven estudiante de enseñanza media vestido con uniforme de colegio, de pie en la antigua sección de Antropología del Museo Nacional de Historia Natural, tallando líticos con habilidad y demostrando ansias por conocer nuevos ámbitos de la investigación arqueológica. Ese Donald estudiante, de pelo corto, con uniforme, muy ordenado y formal, había dado paso a un Donald de pelo largo, barba y jeans, que se había formado como arqueólogo en la Escuela Nacional de Antropología e Historia perteneciente al INAH de México. Empezar a conversar, ofrecerle el estudio del material lítico de Tres Arroyos y notar que su entusiasmo era el mismo de aquel joven estudiante de colegio, fueron una sola cosa.

Publicó el estudio de los materiales líticos de Tres Arroyos, primero en los Anales del Instituto de la Patagonia y luego de manera más completa en su libro Los instrumentos líticos de los primeros 


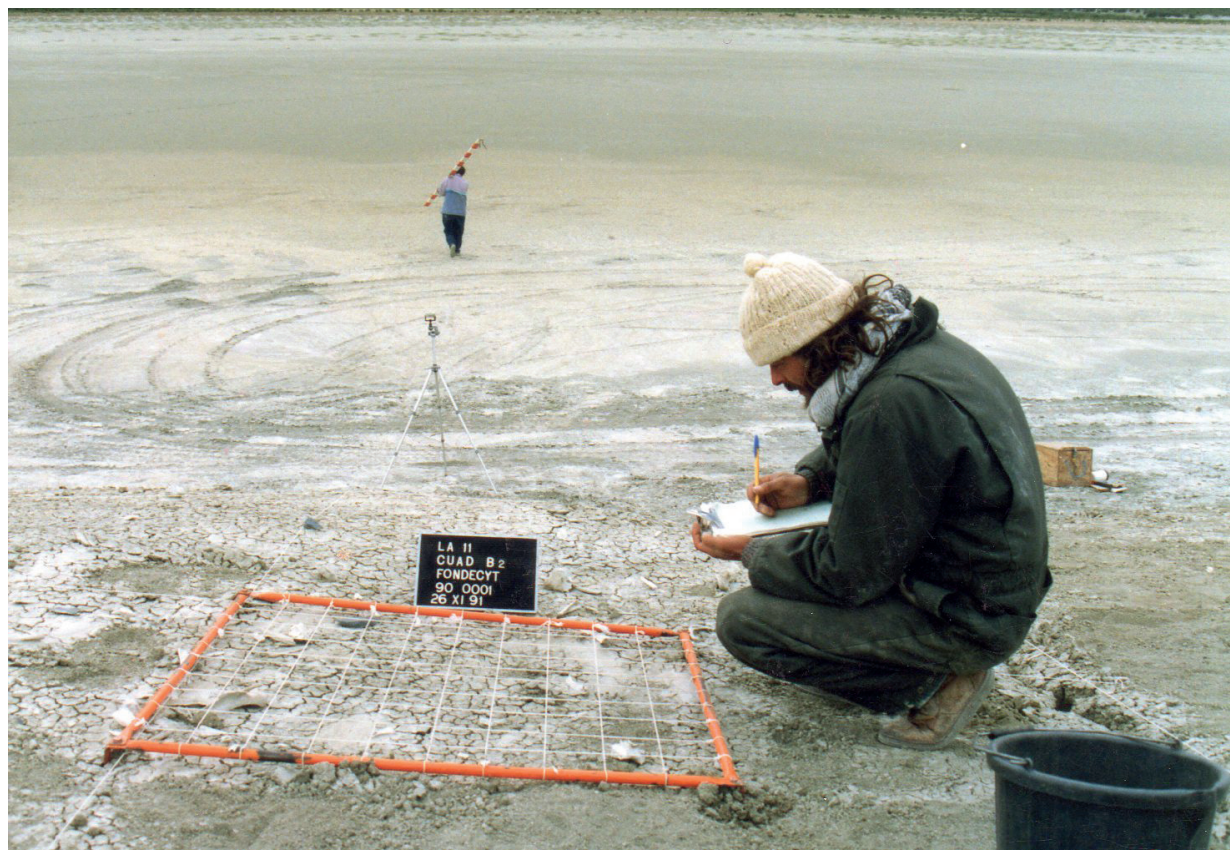

Donald en Tierra del Fuego, 1991 (imagen de Mauricio Massone).

cazadores de Tierra del Fuego que publicó en el año 2002, en la colección de Ensayos y Estudios de la DIBAM.

Su huella profunda no solo quedó en Los Vilos, quedó en México, en Ecuador y en tantos otros lugares y rincones, como en Radal Siete Tazas, en un proyecto conjunto dirigido por Roxana Seguel y Mónica Bahamondez. Recuerdo las largas exploraciones arqueológicas a caballo que compartimos en el Parque Inglés, la cuesta de las Ánimas, la laguna de Mondaca, las vegas de San José, siguiendo la ruta que pasa próxima al volcán Descabezado Grande y al Descabezado Chico, hasta llegar al puesto Fronterizo de Potrerillos, en la región del Maule.

En Tierra del Fuego enriqueció notoriamente nuestro grupo inicial formado también por Alfredo Prieto y Pedro Cárdenas, a quienes se sumaron después diferentes especialistas. Las áreas de experimentación arqueológica que Donald generó y estudió detalladamente en la localidad de Tres Arroyos nos permitió comprender mejor diferentes procesos de formación de los sitios arqueológicos de ese sector estepario.
El tiempo ha pasado muy rápido. Parece tan reciente la nieve que cubrió el sitio arqueológico que excavamos juntos en el Parque Inglés, en la Reserva Nacional de Radal Siete Tazas, durante 1989; o el viento que azotaba las matas de romerillo en la estepa septentrional de Tierra del Fuego, durante nuestra prospección del río San Martín, en 1990; o nuestras conversaciones esenciales mientras las planas y brochas iban rebajando los sedimentos de arena en el sitio de Nagué, al norte de Los Vilos, algunos años después.

Hoy, al escribir estas líneas, siento que ha partido uno de mis grandes amigos de ruta, a quien tuve la suerte de conocer... y me siento más huérfano que ayer. Pero también percibo su alegría de vivir, su fortaleza hasta el final y el compromiso irreductible que asumió con la arqueología, por una profunda e inigualable vocación. Pese a su salud debilitada, logró terminar su tesis doctoral y enviarla a la Universidad Nacional del Centro de la Provincia de Buenos Aires, Olavarría, para su evaluación, pocos meses antes de partir... iQué ejemplo de fortaleza!

Gracias querido amigo, ya nos encontraremos en otra curva del tiempo. 


\title{
La influencia de Donald Jackson en la arqueología de la tierra de la mitad del mundo
}

\author{
Florencio Delgado Espinoza ${ }^{1}$
}

Transcurrían los años ochenta del siglo pasado y la arqueología en América Latina discurría entre posiciones más o menos contrapuestas. Por un lado, la nueva arqueología instaurada en Norteamérica hacía ya más de una década con la figura de Lewis Binford a la cabeza y, por el otro, la llamada arqueología social latinoamericana que surgió en el seno de un grupo de varios arqueólogos de la región con orientación marxista, y que tomó forma como una opción regional frente a la tradición de la historia cultural y la nueva arqueología (Bate 1998; Gallardo 2006; Gándara 2006; Lumbreras 1974; Tantalean 2004). Esta corriente incrementaba su membresía en las esporádicas reuniones tanto en Sudamérica como en México, donde se creó el grupo Evenflo (Bate 1998). En Ecuador, a fines de los setenta del siglo pasado, Jorge Marcos, quien alcanza su doctorado en la Universidad de Illinois, bajo la tutela de Donald Lathrap, con quien además codirigía el proyecto Real Alto en la entonces Provincia del Guayas, funda la Escuela Técnica de Arqueología (1980) en la ESPOL de Guayaquil (Escuela Politécnica del Litoral), que luego se transformó en la Escuela de Arqueología (EDA) y finalmente en el Centro de Estudios Arqueológicos y Antropológicos (CEAA), centro de enseñanza que funcionó de manera regular hasta los años noventa. Alrededor del CEAA, Marcos logró ensamblar a un importante número de arqueólogos latinoamericanos como Luis Guillermo Lumbreras, Miriam Tarragó, Luis Felipe Bate, a lo que se sumaron investigadores de corriente teórica marxista de Estados Unidos, como James Ziedler, Jonathan Damp, Michel Muse, Judith Kried. Desde Argentina se unió la antropóloga social Silvia Álvarez. En este contexto apareció, en 1986, Donald Jackson, un extravagante y “jipi” joven arqueólogo, recibido recientemente en la Escuela Nacional de Antropología e Historia de México bajo la tutela de Luis Felipe Bate, para encargarse de varios cursos que debían operacionalizar el discurso materialista histórico dentro de los estudios de la lítica. Para entonces la exiliada academia chilena se distribuía en varios países, entre ellos, Ecuador y México, donde destacan para el último país la influencia de Bate y Julio Montané, los que junto a Lumbreras y los esposos Mario Sanoja e Iradia Vargas en Venezuela conformaban la base del pensamiento de la arqueología social. Muchos de sus escritos eran mimeografiados y material de consulta obligada de los estudiantes en Perú, Venezuela y ciertamente en el CEAA. Leíamos, también, con mucha atención a Vere Gordon Childe y los principios básicos del materialismo histórico explicado en un texto de la chilena Martha Harnecker. Los debates no concluían en las clases, en realidad empezaban allí y luego se trasladaban a las cantinas y restaurantes del barrio Las Peñas y sus alrededores (como La Langosta, bar El Colonial y la cantina "La Pata de Mazo"), transformada ahora en zona turística, conocida como Malecón 2000. Allí los jóvenes “espolitos”' junto con profesores como Donald discutíamos el materialismo histórico y su aplicación a la arqueología. En los primeros cursos de Donald aprendimos acerca de las evidencias de sitios tempranos como Monte Verde y Pedra Furada no bien conocidos, junto con otros sitios que se gestaban desde el sur y que contradecían los datos y modelos del norte, como "Clovis first". Donald, uno de los más conocedores de la arqueología del paleoindio en las Américas, era más bien partidario de entender los contextos y remitir la discusión a los datos. En Ecuador, sin embargo, Donald tuvo que volcar sus intereses hacia estudios de la tecnología lítica de períodos más bien tardíos de la costa. A su llegada, pocos eran los estudios sobre lítica realizados y se reducían a los que Bell, Mayer-Oakes y Salazar efectuaron sobre contextos de sitios tempranos (Bell 1977; Salazar 1979) y los de Jorge Marcos en la costa.

Para entonces, los estudios de la lítica se nutrían de los aportes metodológicos de huellas de uso

1 Universidad San Francisco de Quito, Colegio de Ciencias Sociales y Humanidades, Diego de Robles y Vía Interoceánica, Quito, Ecuador. fdelgado@usfq.edu.ec. 


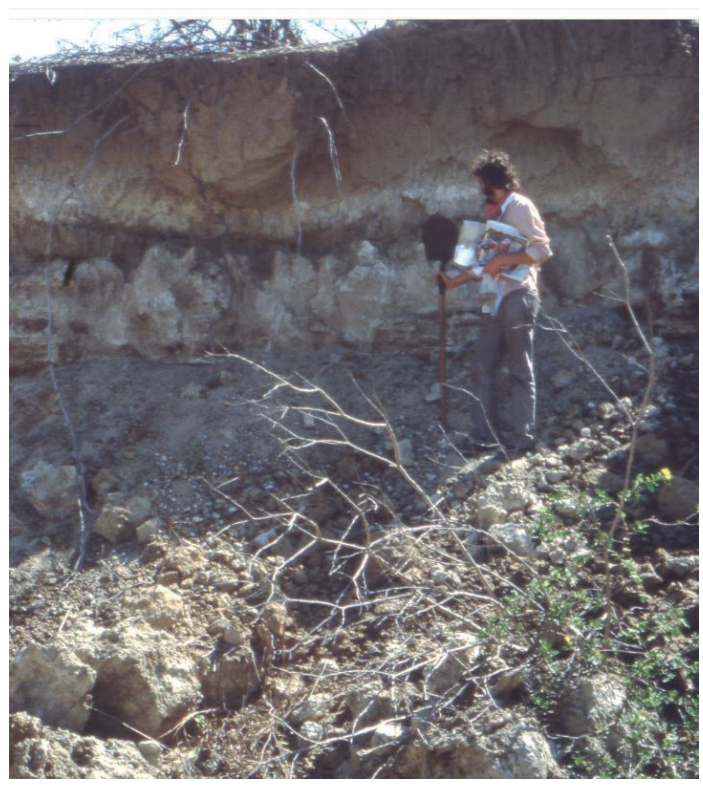

Donald Jackson enero 1987 Rio Real, Ecuador (imagen de Florencio Delgado).

de Semenov y de Kelley acerca de los formatos de clasificación. Sin embargo, Jackson buscaba entender y caracterizar tanto a las fuerzas productivas como las relaciones sociales de producción dentro del proceso productivo de la lítica, con el fin de entender a las formaciones económico-sociales del pasado (Bate 1998).

En su corta estadía en Guayaquil, Donald colaboró en varios proyectos, ya sea como soporte técnico, como encargado del análisis del material lítico o como asistente de investigación. Junto con Jonathan Damp, desarrolló el estudio geoarqueológico del valle del río Real en Chanduy, península de Santa Elena (Damp et al. 1990). En este trabajo pionero demostraron la dinámica de los movimientos de la línea de costa en la zona cercana a Real Alto.

Su mayor contribución fue el desarrollo de varios análisis líticos, entre los que destaca la clasificación morfofuncional y huellas de uso de un conjunto lítico de Salango (Jackson 1987a), un sitio emblemático para el Programa de Antropología para el Ecuador en la región del sur de Manabí, bajo la dirección de Presley Norton. El estudio de Jackson introdujo por primera vez, en la arqueología de la costa ecuatoriana, este tipo de análisis popularizados por el ruso Semenov y que replicó luego, con una visión de la funcionalidad de los artefactos, para el conjunto lítico del sitio rio Cañas de Daule, en la cuenca media del río Guayas, del período Desarrollo Regional, poco entendido en la región (Jackson 1989).

En otro estudio profundizó sobre la técnica bipolar en las sociedades preformativas y formativas de la costa ecuatoriana, antecedido por Stothert (1985) para el grupo precerámico Vegas. En este estudio Donald estableció, comparativamente, continuidades tecnológicas en la talla bipolar, entre otras, desde el precerámico hasta el formativo (Jackson 1987b), lo que continúa siendo clave para entender la tecnología de talla de las sociedades tempranas del Ecuador.

Donald Jackson estuvo en Guayaquil un poco más de dos años, buscando el aporte metodológico a los preceptos de la arqueología social latinoamericana, convirtiéndose en un guía para muchos de nosotros. Personalmente me tocó colaborar en sus análisis como parte del compromiso de estudiante becario en la ESPOL, en los proyectos del CEAA como Peñón del Río, Salango y río Cañas. La incorporación del estudio de huellas de uso para la caracterización tecnológica de la lítica fue un avance que Donald trajo a la arqueología de la costa ecuatoriana. Al final, los difíciles tiempos políticos, tanto en el Ecuador como dentro del CEAA, condujeron a una salida repentina de Donald del Ecuador. Seguramente, muchos proyectos quedaron inconclusos y otros nunca llegaron a gestarse. La partida de Jackson sin duda dejó un gran vacío en el CEAA y en la arqueología del Ecuador. Con los años, Donald siempre tuvo una cercanía al Ecuador y se mantenía informado respecto de la situación de la arqueología del país y seguía de forma cercana a algunos de sus estudiantes. Siempre tuvo voces de aliento hacia los estudiantes y colegas y estuvo presto a compartir de forma desinteresada sus datos. La arqueología ecuatoriana siente su influencia, por lo que será recordado y muy apreciado en la tierra de la mitad del mundo. 


\title{
Referencias Citadas
}

Bate, L.F. 1998. El Proceso de Investigación en Arqueología. Crítica, Barcelona.

Bell, R.E. 1977. Obsidian hydration studies in highland Ecuador. American Antiquity 42:68-78.

Damp, J.E., D. Jackson, P. Vargas y P. Zambrano 1990. On the waterfront: quaternary environments and the formative occupation of southwestern Ecuador. Geoarchaeology 5:171-185.

Gallardo, F. 2006. Comentario a "Arqueología y Sociedad" de Luis Guillermo Lumbreras. Chungara Revista de Antropología Chilena 38:50-151.

Gándara, M. 2006. Reseña a Arqueología y Sociedad de Luis Guillermo Lumbreras. Chungara Revista de Antropología Chilena 38:145-149.

Jackson, D. 1987a. Clasificación morfo-funcional y análisis de huellas de uso en un conjunto lítico del sitio arqueológico de Salango. Miscelánea Antropológica Ecuatoriana 7:59-90.
Jackson, D. 1987b. Percusión bipolar en instrumentos líticos tempranos de la costa del Ecuador. Gaceta Arqueológica Andina 14:6-9.

Jackson, D. 1989. Análisis funcional de instrumentos líticos del sitio Río Cañas, Río Daule. Miscelánea Antropológica Ecuatoriana 8:101-117.

Lumbreras, L.G. 2005. Arqueología y Sociedad, editado por Enrique González Carré y Carlos del Águila. Instituto de Estudios Peruanos, Museo Nacional de Arqueología y Antropología, INDEA, Lima.

Salazar, E. 1979. El Hombre Temprano en la Región del Ilaló, Sierra del Ecuador. Publicaciones Departamento de Difusión Cultural de la Universidad de Cuenca, Cuenca.

Stothert, K.E. 1985. The preceramic Las Vegas Culture of coastal Ecuador. American Antiquity 50:613-637.

Tantaleán, H. 2004. L' arqueología social peruana: ¿mite o realitat? Cota Zero 19:90-100.

1 Espolitos era el término con el que se describía en la época a los estudiantes del CEAA-ESPOL.

\section{Pensar en Donald es pensar en libertad y su extraño y maravilloso vínculo con el pasado}

\author{
Daniela Osorio ${ }^{1,2}$
}

Está vivo el recuerdo,

De su cabello al viento y sus ojos azules Se le puede ver en las playas de Los Vilos

En una cueva escondida

$\mathrm{O}$ en los resabios de una fogata encendida al anochecer.

Fuiste verbo en la palabra Maestro Incesante caminante de parajes naturales Incesante constructor de historias y relatos

en cada piedra apareces

en el océano apareces

Oh cazador recolector del presente Si hasta el pasado te extraña
Pensar en Donald es pensar en libertad, en acción constante y en alegría de vivir. Recuerdo cuando lo conocí, desde la timidez de la silla de estudiante, entrando a la sala con sus típicas zapatillas blancas, camisa y jeans. De pelo largo, asombraba su delgadez, sus ojos claros y el humo de su cigarrillo. Pero sabemos que las imágenes son solo una capa y que no se conoce a una persona sino hasta verla actuar, hablar, reír. Y el hombre apasionado por la arqueología apareció entonces en cada una de sus palabras, de sus dibujos en el pizarrón y en su caminar nervioso. Una especial atmósfera nos condujo a conectarnos con ese remoto pasado, de los cazadores recolectores, de

1 Institute of Archaeology, University College London, 31-34 Gordon Square, London WC1H 0PY, United Kingdom. daniela.osorio.15@ucl.ac.uk

2 Laboratorio de Arqueología y Paleoambiente, Instituto de Alta Investigación, Universidad de Tarapacá, Antofagasta 1520, Arica 100236, Chile. 
los largos viajes, de la tierra, la piedra, el sol y el agua. Creo que no fue hasta que compartí en terreno con él que pude entender finalmente ese extraño y maravilloso vínculo que Donald tenía con el pasado y que se expresaba en cada una de sus clases y en su trabajo profesional. Porque Donald sabía cómo ser arqueólogo de tiempo completo, para él, la arqueología no era solo sentarse a escribir, sino que salir al campo a buscar y a pensar; nunca fue simple recolector de datos y números. Él recolectaba experiencias.

Recuerdo los innumerables diálogos de pasillo acerca de antiguas sociedades, o de algún tema particular de sus clases, ya que siempre tenía tiempo para conversar. Y al día siguiente nos esperaba en su oficina con una inmensa cantidad de fotocopias para leer, pues sabía que en esta tarea descabellada de tratar de entender a personas que jamás conoceremos, teníamos que leer, analizar, cuestionar, criticar, movilizarnos, no ser meros replicadores, ser gestores, ser responsables al momento de hablar por aquellos ya en silencio.

Entrar a su oficina era también entrar a un mundo diferente, lleno de cajas, de réplicas talladas, de fotos, en fin, de diversas cosas, pero por sobre todo lleno de piedras; un universo en un pequeño espacio. Y ahora pienso en esas piedras, ¿qué más resistente, pero a la vez más maleable que las piedras? Como el mismo Donald, fuerte, pero siempre humilde, siempre abierto a compartir lo que sabía, siempre dispuesto a entregar alguna sonrisa con sus variados chistes y buen humor. Creo que por eso todos los que tratamos de estudiar lítica en Chile lo consideramos nuestro maestro. Él nos enseñó a amar las piedras, a entender cada arista, cada color, cada textura; Donald nos motivó en el desafío de que, a partir de esa dureza, llegaríamos al gesto, al movimiento realizado por inmemorables artesanos.

Sus enseñanzas, finalmente, son mucho más que información y relatos. Las lecciones de Donald van por el lado de la ciencia como un modo de vida, pero no alejado de la comunidad, no aislado, no aséptico elevado en una atalaya. No, la ciencia de Donald estaba en la tierra, en su amado Los Vilos, en la observación y experimentación de esas playas y los pescadores, en la comprensión de las mareas y los animales marinos, en el recorrido de los parajes y sitios arqueológicos en un intento como decía él de "pensarlos".
Porque Donald sabía que la arqueología no tenía sentido en el libro, y por eso siempre fue abierto a la comunidad, para compartir los relatos arqueológicos y, al mismo tiempo, aprender de la gente. Y sí, los vileños saben que allí vivieron otras gentes que cazaron grandes animales y pescaron en sus playas, hace miles de años, entonces podemos ver esa difusa línea del tiempo que conecta lo que hacemos con el presente: el sentido social de nuestro quehacer como arqueólogos.

Tuve la oportunidad de ser invitada a excavar en Santa Julia y fue una experiencia inolvidable. Las palabras de recibimiento cuando llegamos a su casa fueron: "a ver a ver chiquillos, no hay arqueólogo que le guste el Paleoindio y que no le guste el whisky". Pero esas palabras fueron solo un juego, el punto de partida para largas conversaciones luego de cada jornada, de risas, de aprendizajes en el campo, de sentir el compañerismo y de disfrutar cada momento, tal como él lo hacía. Porque para Donald, hacer una clase, compartir una mesa con amigos, disfrutar de un buen vino, conversar hasta altas horas de la noche, bailar vallenatos y estar en fiesta, en fin, cada momento era adecuado para pasarlo "macanudo". Era una excusa para sonreír. Incluso durante su enfermedad, nunca bajó los brazos. Su voz por el teléfono se notaba más débil, pero sus palabras eran las de siempre. Verlo era realmente un ejemplo para todos, para él la enfermedad era solo un recodo en el camino, un desvío de ruta, porque como buen caminante sabía que había nuevos senderos, y que al igual que durante toda su vida, lo importante era seguir disfrutando de lo que tanto amaba, su familia y su arqueología.

Recuerdo la última vez que lo vi. Nos invitó a su casa y cocinó su clásica y exquisita comida mexicana. Siempre fue el mismo, el mismo Donald. Se levantó de la mesa y trajo un artículo en donde estaban armando una réplica con su querido amigo Cesar Méndez. En verdad inagotable, apasionado, desbordante de ideas y de esa energía de vida que tantas veces nos falta.

Sé, como dijo su hermano Douglas en la ceremonia de despedida, que "Donald está feliz nadando en las costas de su amado Los Vilos, donde también nadaron aquellos primeros pobladores hace 13 mil años, que él tanto buscó". Lo imagino pescando, tallando algunos instrumentos. Lo imagino caminando por esas hermosas playas, sintiendo la brisa marina en su rostro, y diciendo, "qué descueve". 


\title{
Donald Jackson un arqueólogo apasionado, alegre y sencillo
}

\author{
Paula C. Ugalde 1,2
}

Pensando en una cualidad para recordar y destacar a Donald vuelvo al pasado y a los momentos que compartimos y llego a esto: Donald fue alguien que hacía buenas cosas en silencio, sin aspavientos. Él tomaba cosas sencillas pero importantes y las incorporaba silenciosamente a su rutina, como si fueran naturales para él: un ejemplo muy lindo es el compartir y valorar a los demás por lo que son.

Mi primer acercamiento personal a Donald fue durante las clases de arqueología lítica en la Universidad de Chile, durante el 2005. Allí, como era costumbre, cuestionaba lo que me decían los profesores, con el ímpetu y pasión que caracteriza a la juventud aprendiendo cosas nuevas. Dado mi comportamiento, cuando Donald se acercó a ofrecerme hacer la práctica profesional en su proyecto de investigación, que tenía como sitio estrella a Santa Julia, me sorprendí mucho y le pregunté por qué me estaba dando esta oportunidad (pues me interesaban los períodos más tardíos de la prehistoria, y sinceramente hasta ese entonces, jamás había pensado en la lítica como parte de mi futura carrera profesional). Él me dijo, con su característica sonrisa picarona, que se debía a un comentario que le había hecho, de corte feminista, criticando la visión masculina que usualmente domina y permea las perspectivas acerca de períodos tempranos de cazadores-recolectores. Me vi sorprendida de que se hubiera fijado en una persona que comúnmente le llevaba la contraria. Por eso y por la oportunidad que se me abría, le dije que sí, sin pensar en que luego, una serie de eventos desencadenarían en mi memoria de título, guiada por él y marcarían mi vida profesional hasta el día de hoy.

Con esto no quiero contar mi historia, sino recalcar que Donald sabía ver -y a veces entreverlas potencialidades y las cosas buenas de las personas, incluso antes de que salieran al aire. Esto era posible, creo yo, por la sencillez y alegría con que él afrontaba la vida, sin quitar su perspectiva crítica y la suma seriedad y vital pasión con la que se tomaba su trabajo. En terreno, esa valoración por compartir se notaba en cosas también sencillas, como preocuparse de que todos los que fumábamos tuviéramos cigarros (o café, o un whisky). Todos los elementos que para él propiciaban una conversación, una discusión arqueológica, o simplemente risas y bailes. Este es solo un pequeño homenaje de una de sus alumnas, a dos de sus características más hermosas: la alegría y la sencillez. Ahora, desde la lejanía que brinda el tiempo y la geografía, me doy cuenta de lo mucho que te debo como arqueóloga, la gratitud que siento y lo mucho que admiré tu apertura de mente para aceptarnos a todos tal y como somos. Te extraño querido Donald.

School of Anthropology, University of Arizona, Tucson, AZ 85721-0030, USA. arqueo.paulaugalde@ gmail.com

2 Laboratorio de Arqueología y Paleoambiente, Instituto de Alta Investigación, Universidad de Tarapacá, Antofagasta 1520, Casilla 6-D, Arica 100236, Chile. 


\title{
Donald Jackson arqueólogo chileno para las Américas
}

\author{
Calogero M. Santoro ${ }^{1}$
}

A su entrañable compañera Roxana Seguel

El 14 de junio a las 17:51 horas de 2015 es la última llamada perdida de Donald Jackson registrada en mi teléfono portátil. Luego me comunicó, con cierto pesar, que por indicación médica debía bajar el ritmo y preocuparse de su salud, por lo se restaba del equipo de continuidad del nuevo proyecto FONDECYT que armábamos en esos días. Nos reunimos varias veces después y la última que lo vimos, con César Méndez, pocos días antes de su partida, seguía optimista y lleno de planes como siempre. Nosotros lo mirábamos entre asombrados y profundamente conmovidos. "Qué les pasa, nos dijo, por qué tanta tristeza, todavía no me voy a morir".

Así Donald convenció a medio mundo que seguiría adelante, a pesar de todo, ayudado por la medicina pero más que nada de los dioses Maya, que imaginaba lo liberarían del mal y le darían un nuevo soplo de vida; como me dijo la primera vez que nos vimos una vez diagnosticada la enfermedad. Por esta razón cuesta todavía aceptar que no está físicamente en el mundo arqueológico, que fue su máxima pasión de vida.

A $\operatorname{los} 16$ años Donald le escribió una conceptuosa carta a Guillermo Focacci, Director del Museo San Miguel de Azapa de la Universidad del Norte en Arica. En ella le explicaba su interés y pasión por la arqueología, cuando recién cursaba enseñanza media y en virtud de ello le solicitaba el envío, a modo de donación, de la colección completa de Chungara, que en ese momento, 1977, contaba solo con cinco números editados e impresos. Esta inusual petición fue discutida en el pequeño grupo que conformaba el personal del Museo (Jorge Hidalgo, Liliana Ulloa, Julia Córdova, Iván Muñoz y el suscrito). Treinta y tres años más tarde, en el contexto del XV Congreso Nacional de Arqueología Chilena realizado en Arica, Donald recordó en el homenaje que la Sociedad Chilena de Arqueología le rindió a Guillermo Focacci la respuesta positiva de Focacci que no solo incluyó la colección completa de la Revista, sino que además dio origen a una larga relación epistolar. Donald valoró ese gesto como parte del importante aporte de Guillermo Focacci, pionero de la arqueología de Arica y gran artífice de la creación de la colección arqueológica que actualmente custodia el Museo Arqueológico Universidad de Tarapacá, en Azapa, Arica, "pionera en el estudio de los primeros habitantes que poblaron estos territorios" (Jackson 2004:8).

Donald Jackson, en cambio, forjó un modo alternativo a la tradicional manera de hacer arqueología chilena de aquella época, especialmente el trabajo aparentemente individual e individualista de una arqueología que se reproducía a sí misma, de carácter parroquial, a pesar que se levantaban temáticas más generales que se circunscribían, en el caso del norte de Chile, al área Centro-Sur Andina. La escuela de Donald radicó en generar e integrar equipos de colaboración científica dentro de la arqueología, que abrió luego hacia otras disciplinas, poniendo como eje a la sociedad humana, a la mujer y hombre prehistórico, que generaron "la gran riqueza, diversidad y complejidad de las sociedades del pasado" (Jackson 2004:8).

Como docente de la Universidad de Chile, institución a la que ingresó en 1993, generó también un ambiente de colaboración y enseñanza con los estudiantes. Esta práctica pedagógica la aprendió mirando cómo se excavaba el sitio Quereo en 1976, en los Vilos (Núñez 2015), su tierra natal y casa central de su propia investigación, donde aplicó este principio marxista de teoría y praxis (Massone 2016 este número). Impulsó la idea que la arqueología no se agota en los límites políticos de una comuna, una provincia, o una región, o en límites de parcelas o feudos arqueológicos, muy evidentes hasta hace pocos años, pero no completamente erradicados de la disciplina en general. Donald es uno de los

\footnotetext{
1 Laboratorio de Arqueología y Paleoambiente, Instituto de Alta Investigación, Universidad de Tarapacá, Antofagasta 1520, Arica 100236, Chile. Fonos IAI: 56-58 228-0334, Laboratorio: 56-58 220-5896. calogero_santoro@ yahoo.com
} 
pocos arqueólogos chilenos que han transitado por casi todos los territorios del país, desde Arica hasta Punta Arenas, desde el Desierto de Atacama hasta Magallanes, movido por problemas de investigación (Massone 2016 este número). Con ello cambió el paradigma de una arqueología territorial, a una arqueología de problemas sociales, que enfrentaba dentro de distintos ecosistemas.

El interés de tratar de explicar el poblamiento temprano de Sudamérica hizo que nuestros caminos se encontraran, por el mutuo interés, en ambientes extremos y el problema arqueológico del poblamiento inicial de Sudamérica.

Este encuentro se facilitó por medio de dos brillantes discípulas de Donald estudiantes de la Carrera de Antropología-Arqueología de la Universidad de Chile, como Daniela Osorio, actualmente becaria CONICYT en el programa de doctorado en la University College London, y Paula Ugalde quien realiza sus estudios doctorales en la University of Arizona, Tucson, USA (Osorio 2016 este número; Ugalde 2016 este número). Ambas, siguiendo la impronta del maestro, estudian tecnología lítica con visiones metodológicas y teóricas distintas, pero complementarias a la tradición morfológica-cronológica-cultural. Con Daniela y Paula integradas con sus prácticas profesionales al proyecto interdisciplinario respecto de primeros poblamientos humanos en el desierto de Atacama, lograron generar lazos de colaboración académica, lo que no se homologa en los niveles superiores de toma de decisión académica. Si hubiéramos tenido que esperar los acuerdos oficiales para la realización de este círculo virtuoso, posiblemente todavía estaríamos en las negociaciones de convenios tratados por staff de abogados, para definir protocolos abstractos de colaboración. Tanta legalidad y precedentes burocráticos pueden aniquilar iniciativas de esta naturaleza. Chile es un país pequeño e insular, más bien precario, como sentenció una vez el escritor José Donoso, que tiende a transformar su interior en un archipiélago de pequeñas islas políticas, académicas, no así económicas.

Donald fue contra este statu quo y promovió la colaboración mediante sus estudiantes y por participar activamente en distintos equipos y territorios para aportar a la comprensión acerca de las primeras sociedades humanas que habitaron los distintos territorios de Sudamérica. Con sus estudiantes han roto de alguna manera la insularidad, y con ello como si se estuviera comenzando a construir un gran "Qapaq Ñan" académico, que debería integrar no solo las islas del país sino del área andina y Sudamérica en general.

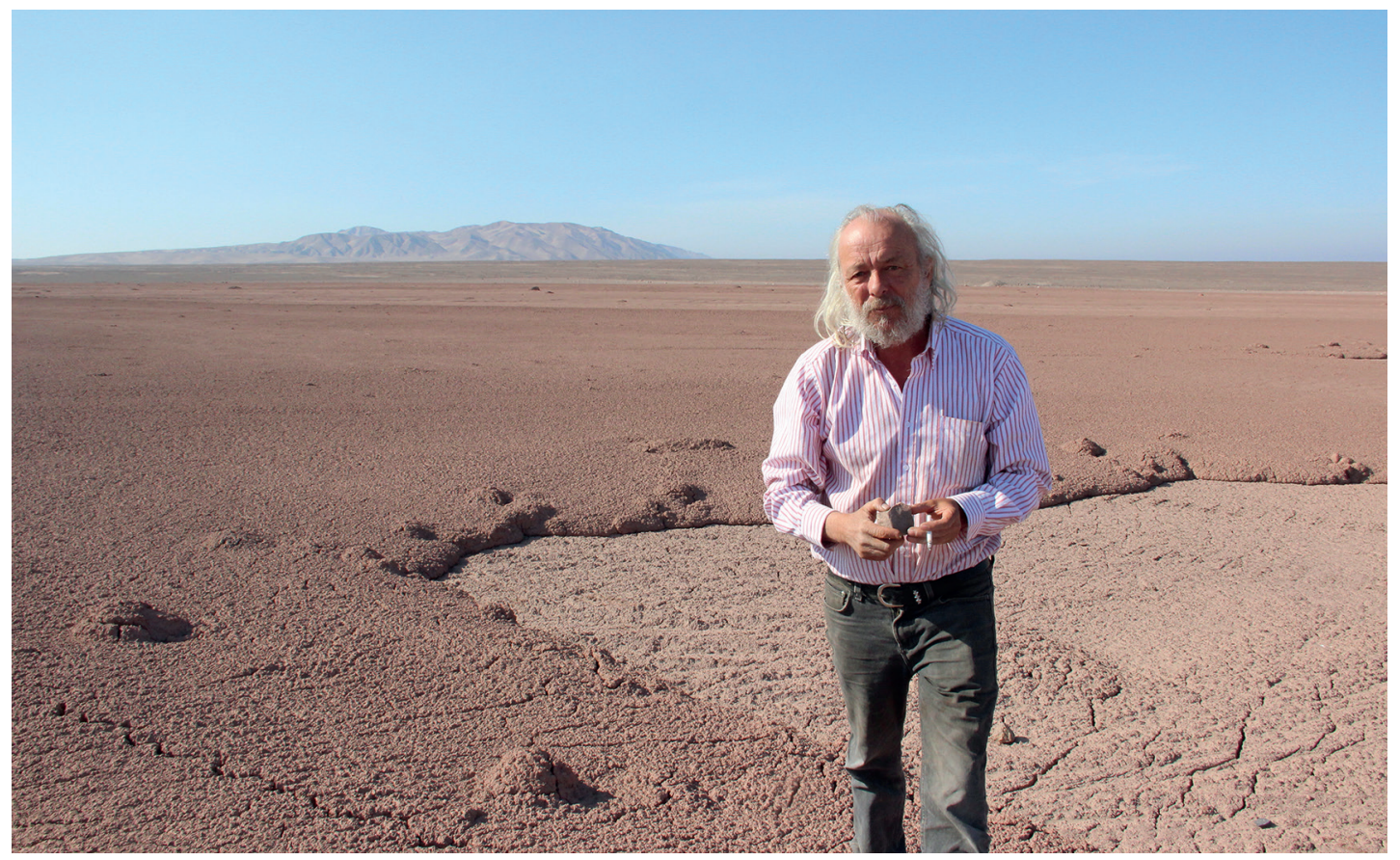

Donald Jackson en pleno desierto de Atacama (Pampa del Tamarugal), octubre 2012 (imagen de Calogero Santoro). 


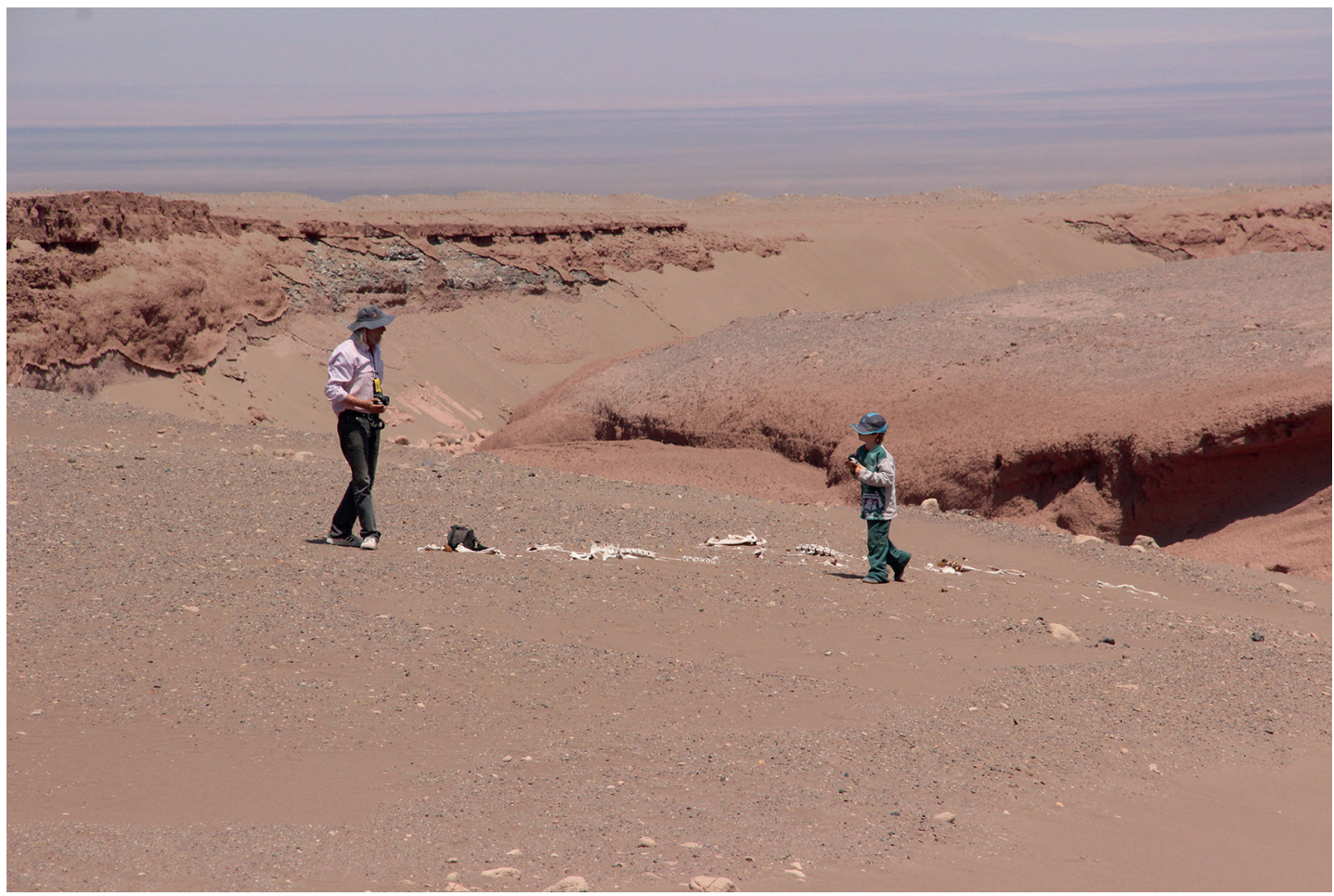

Donald Jackson en quebrada Chipana con Elliot, registrando restos de mulares empampados, octubre 2012 (imagen de Calogero Santoro).

Donald estudió en México y pudo terminar la carrera sin problemas porque en su tiempo había desaparecido la cláusula de demostrar el manejo de dos lenguas vernáculas, que limitó a Carlos Ponce Sanjinés a graduarse en México (Enrique Soruco, comunicación personal, La Paz invierno 1990). Independiente de esta situación, Donald desarrolló una manera distinta de enfrentar el pasado mediante la vivencia etnográfica y la experimentación. La riqueza de vivenciar y experimentar el pasado durante su vida, Donald soñó alguna vez con traspasarla a su nieto, a quien, como señaló su hermana en la ceremonia religiosa de despedida, no pudo tejerle una red para salir juntos a pescar. Esta actividad la realizó por años en Los Vilos en vacaciones de verano, que transformaba en un laboratorio experimental natural. La idea de pescar en la costa del norte semiárido comiendo lo que arrojara la red y conversar de la vida, plan del que hablamos en más de una oportunidad, quedó también pendiente entre nosotros.

En su periplo de regreso a Chile desde México Donald se detuvo en Ecuador (Delgado 2016 este número) y también en Colombia, donde conoció a la mujer con la que tuvieron a su hijo Cané. Parafraseando a Violeta Parra este Run-Run ${ }^{1}$ (González 2006) siguió hacia el sur dejando en el norte amigos, discípulos y amores entrañables, que acá se multiplicaron en los escenarios de la vida y de la academia que Donald fundió en un solo elemento (Méndez 2015; Núñez 2015).

\section{Referencias Citadas}

Delgado, F. 2016. La influencia de Donald Jackson en la arqueología de la tierra de la mitad del mundo. Chungara Revista de Antropología Chilena 48:??.
González, J.P. 2006. Migración amorosa y musical en "Run Run se fue pa'l norte" de Violeta Parra. Ensayos. Historia y Teoría del Arte 11:173-185. 
Jackson, D. 2004. Discurso inaugural del IX Congreso Nacional de Arqueología Chilena, 16 de octubre de 2000. Chungara Revista de Antropología Chilena 36:8.

Méndez, C. 2015. In memoriam Donald Guillermo Jackson Squella (1960-2015). Revista Chilena de Antropología 31:7-9.

Núñez, L. 2015. La apasionada obra de Donald Guillermo Jackson Squella y su muerte inesperada (1960-2015).
Estudios Atacameños Arqueología y Antropología Surandinas 51:9-13.

Osorio, D. 2016. Pensar en Donald es pensar en libertad y su extraño y maravilloso vínculo con el pasado. Chungara Revista de Antropología Chilena 48:480-481.

Ugalde, P.C. 2016. Donald Jackson un arqueólogo apasionado, alegre y sencillo. Chugara Revista de Antropología Chilena 48:482.

\section{Nota}

1 Canción de Violeta Parra: "Run Run se fue pa'l norte", 1967. 